\title{
Divulgando A Psicologia No Rádio: Relato de Uma Experiência $^{1}$
}

\author{
Broadcasting Psychology On The Radio: \\ An Experience Report
}

Divulgando La Psicología En La Radio: Relato De Una Experiencia

Adriano Roberto Afonso do Nascimento, Isabela Dias Ribeiro, Isabella Ferraz Lacerda de Mello, Lucas Eduardo Guimarães \& Luciano Inácio Mariano Universidade Federal de Minas Gerais
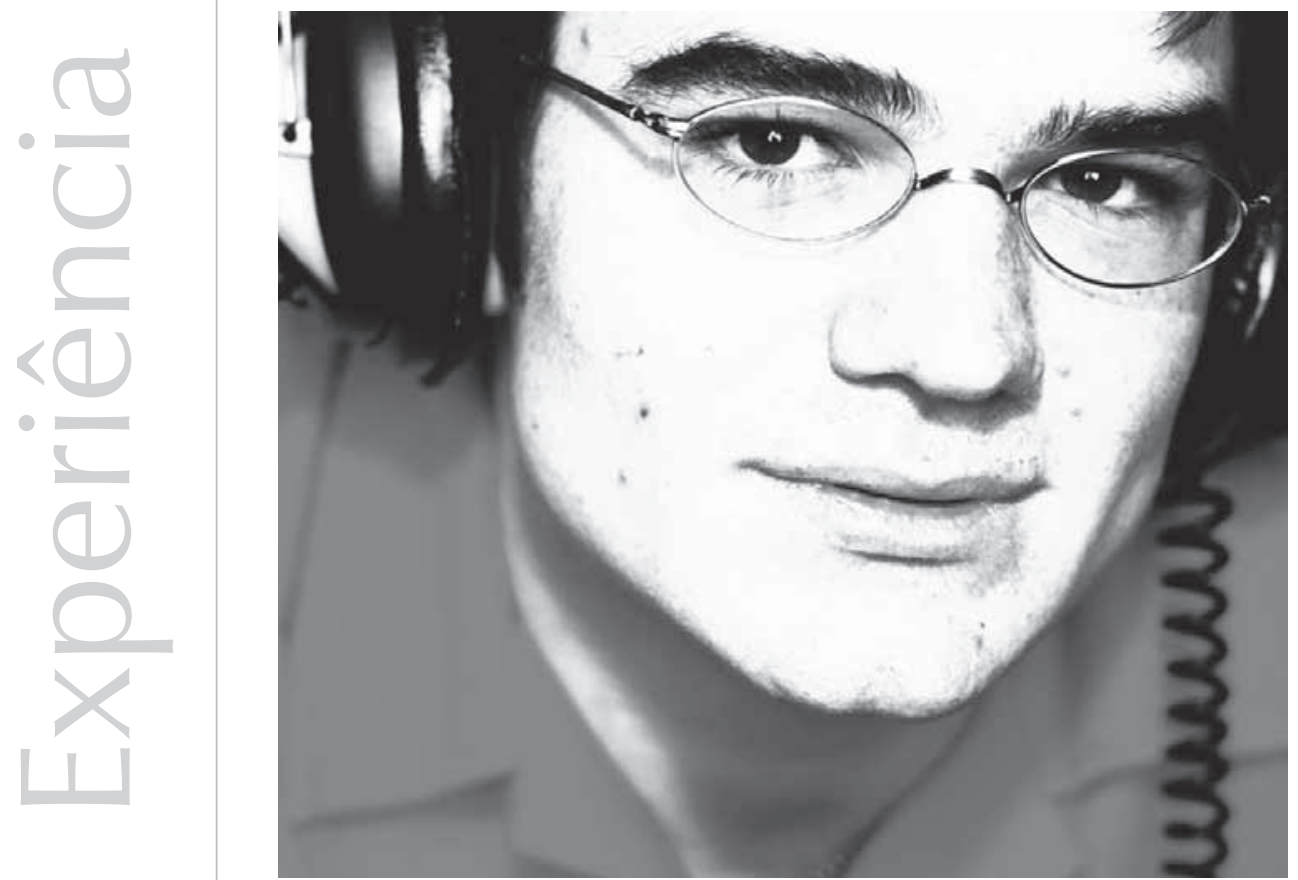
Resumo: Em virtude das inúmeras dificuldades envolvidas no seu processo de planejamento e de execução, a divulgação científica tem tradicionalmente representado um desafio para pesquisadores de diversas áreas. Apesar da reconhecida importância dessa tarefa, é preciso admitir que a própria Academia tem dedicado a ela insuficiente atenção. O relato aqui apresentado descreve o processo de produção semanal de um programa de rádio que tem como objetivo, utilizando o saber psicológico como uma de suas referências, abordar temas cotidianos. Foram produzidos, até o momento, 20 programas com duração média de 15 minutos. É destacada no relato a importância da atividade de divulgação científica baseada na interlocução de saberes. São descritas as principais dificuldades enfrentadas pela equipe quanto à linguagem e aos aspectos técnicos da produção dos programas e as soluções encontradas na busca por um formato que conjugue a responsabilidade ética no tratamento dos temas, a fidelidade aos pressupostos teóricos dos entrevistados e a acessibilidade da linguagem para um público não especialista em Psicologia.

Palavras-chave: Comunicação científica - Psicologia. Rádio. Comunicação e divulgação científica

Abstract: The diffusion of science knowledge has traditionally represented a challenge for researchers from several areas given the abundant difficulties involved in its planning and execution. Despite the acknowledged importance of this task, it is clear that the universities themselves have not been giving enough attention to this matter. The present report describes the process of a weekly production of a radio program that is aimed at approaching everyday themes using psychological knowledge as one of its references. 20 programs were produced so far with an average duration of 15 minutes each. The importance of the diffusion of science based upon knowledge dialogue is highlighted in this report. Also, here are described the main difficulties faced by the team regarding language and the technical aspects of the production of the radio programs and the solutions found in the search for a format that combines the ethical responsibility in addressing the themes, loyalty to the theoretical assumptions of the interviewees and language accessibility to a public non-specialist in psychology.

Keywords: Scientific communication-Psychology. Radio. Scientific Communication and Diffusion .

Resumen: En virtud de las innumerables dificultades involucradas en su proceso de planeación y de ejecución, la divulgación ha representado tradicionalmente un desafío para investigadores de diversas áreas. A despecho de la reconocida importancia de esa tarea, es necesario reconocer que la propia academia ha dedicado a ella insuficiente atención. El relato aquí presentado describe el proceso de producción semanal de un programa de radio que tiene como objetivo, utilizando el saber psicológico como una de sus referencias, abordar temas cotidianos. Han sido producidos, hasta el momento, 20 programas con duración promedio de 15 minutos. Es destacada en el relato la importancia de la actividad de divulgación científica basada en la interlocución de saberes. Son descriptas las principales dificultades enfrentadas por el equipo en cuanto al lenguaje y a los aspectos técnicos de la producción de los programas y las soluciones encontradas en la búsqueda por un formato que conjugue la responsabilidad ética en el tratamiento de los temas, la fidelidad a los presupuestos teóricos de los entrevistados y la accesibilidad del lenguaje para un público no especialista en psicología.

Palabras clave: Comunicación científica-Psicología. Radio. Comunicación y divulgación científica

1 Agências de financiamento: Fundação de Amparo à Pesquisa do Estado de Minas Gerais/FAPEMIG e Pró-Reitoria de Extensão/UFMG
Também presente na internet, nos telefones celulares e nos players de última geração, contrariando os prognósticos mais pessimistas, o rádio se mantém como veículo de comunicação importante. A utilização desse veículo, desde 1923, a partir da fundação da Rádio Sociedade do Rio de Janeiro, como meio de divulgação científica no País esteve quase sempre sujeita às turbulências políticas que caracterizaram nosso século XX. Tradicionalmente transmitidos por emissoras associadas ao poder público, os programas que se propunham a veicular e a discutir ciência e tecnologia seguiam, assim, as diretrizes políticas oficiais sobre o que devia ou não ser informado aos ouvintes. No contexto atual de presumida maior liberdade na circulação de ideias e de informações, o rádio, sobretudo o ainda vinculado a instituições públicas de ensino superior, continua sendo veículo privilegiado de divulgação científica, agora também como espaço possível de interlocução entre o que é produzido na Academia e outras formas de conhecimento socialmente partilhado.

Nesse sentido, segundo Sandra de Deus, uma rádio universitária 
"deve ser um canal de perspectivas esclarecedoras dos problemas sociais e das contradições políticas e econômicas, procurando dar visibilidade para as diferentes formas de expressão artística, e, por fim, deve representar a multiplicidade de ideias, gostos e correntes do contexto social" (2003, p. 317)

Nessa proposta, que claramente busca privilegiar a diversidade de discursos sociais, as atividades de divulgação científica ocupariam, como esperado em uma instituição de ensino, um espaço que poderia ser entendido como articulador democrático dessa diversidade. Entretanto, não tem sido sempre assim.

popularização da ciência se baseou no pressuposto de que o público deve ser educado e ensinado a compreender as teorias científicas 'corretamente'. Nesses intentos está a premissa subjacente de que, seja o público, sejam os 'nativos', sejam as pessoas leigas, todos devem abandonar as crenças que possuem e ascender a uma forma superior de conhecimento, oferecida por especialistas e tecnocratas (2008, p.94)
Como reconhece Albagli, "atividades (de divulgação da ciência e tecnologia) podem tanto servir como instrumentos de maior consciência social sobre a atividade científica, seu papel e importância atuais para a sociedade, como podem ser instrumentais para a mistificação da opinião pública sobre a ciência" (1996, p. 402).

Portanto, um dos objetivos desejáveis da divulgação científica seria, partindo do reconhecimento de que a ciência é o empreendimento coletivo de um conjunto diversificado de atores (Silva, 2006), proporcionar à sociedade informações que pudessem permitir maior controle social sobre a atividade científica (Assumpção, 2003), fomentando uma participação mais informada de diversos segmentos sociais inclusive na definição de prioridades de investimento e na discussão sobre possíveis desdobramentos tecnológicos úteis para a vida cotidiana (Maciel \& Silva Jr., 2006; Sabbatini, 2004; Caldas, 2003).

O desafio aos que se propõem a trabalhar com divulgação científica parecer ser o de, ao buscar esse objetivo, evitar que, na prática, sua atividade não tenha como resultado contribuir para a manutenção da imagem da ciência como algo inacessível aos não iniciados.
Infelizmente, parece ser essa última possibilidade o resultado mais comum da maior parte dos projetos de divulgação científica.

Uma série de elementos parece contribuir especialmente para que não consigamos com maior frequência concretizar os objetivos de uma divulgação científica baseada na interlocução democrática de saberes. O primeiro desses elementos seria a existência, ainda, de uma tendência representativa que considera a divulgação científica uma atividade unidirecional (cientista $\rightarrow$ leigo), baseada no chamado modelo do déficit, pelo qual a população (analfabetos em ciência) recebe "o conteúdo redentor de um conhecimento descontextualizado e encapsulado" (Moreira \& Massarani, 2002, p. 62). Na base dessa tendência, encontrase claramente a crença de que existe uma hierarquia entre os saberes científicos e os populares. Segundo Jovchelovitch,

a idéia de popularização da ciência se baseou no pressuposto de que o público deve ser educado e ensinado a compreender as teorias científicas 'corretamente'. Nesses intentos está a premissa subjacente de que, seja o público, sejam os 'nativos', sejam as pessoas leigas, todos devem abandonar as crenças que possuem e ascender a uma forma superior de conhecimento, oferecida por especialistas e tecnocratas (2008, p.94)

Como dificuldade de caráter prático, somase a isso o fato de que, se há, por um lado, uma percepção bastante difundida sobre a necessidade de tornar conhecidos resultados de pesquisas produzidas no País, em sua maior parte com dinheiro público (Oliveira, 2001), persiste também o problema já tradicional quanto à transmissão do conhecimento científico, mas não só dele, que é o da tradução/traição. Esse processo, centro do embate já conhecido entre cientistas (Ruivo, 2004) e entre cientistas e jornalistas (Albagli, 1996), tem feito com que alguns pesquisadores tomem para si a responsabilidade pela 
divulgação do conhecimento produzido por um determinado campo da ciência, ainda que, entre pares, essa atividade seja recorrentemente considerada, para um cientista, como de mais baixo status (Mueller, 2002). Entretanto, quanto a essa alternativa, é necessário reconhecermos que, ao se concentrar exclusivamente na forma da mensagem, reitera-se a concepção da existência de um receptor indiferenciado. Desconsidera-se, por exemplo, que diferentes grupos se apropriam de uma determinada mensagem também a partir de suas próprias referências, e não somente devido às características da própria mensagem (Moscovici, 1978).

Mesmo quanto às características do emissor, é preciso admitir que tanto cientistas quanto divulgadores não cientistas não escapam de posicionamentos sociais que dão suporte ao próprio processo de comunicação. De fato, já se admite que tais posicionamentos não sejam algo a ser evitado como ruídos sociais que podem contaminar a mensagem (Gonçalves, 2008). Entender a democratização do conhecimento científico como baseada em um processo de alfabetização e não em uma interlocução efetiva com outras formas de saber, interlocução que deve contemplar as diferentes características dessas formas e suas âncoras sociais, pode nos manter distantes de um objetivo recorrentemente evocado por divulgadores da ciência, o de contribuir para a transformação de uma sociedade consumidora de informação científica em uma de cidadãos.

Um outro elemento complicador a ser considerado nessa discussão é que a veiculação de informações sobre a ciência nos meios de comunicação tem sido guiada mais por referências a acontecimentos do que pelo conjunto de conhecimentos no qual se insere o próprio acontecimento (Guimarães, 2001). Além disso, destaca-se quase sempre nessa veiculação aquilo que é exótico, espetacular, original, o que realmente contribui para uma certa mistificação do que seja a atividade cotidiana do cientista (Albagli, 1996; Pechula, 2007; Wernek, 2002; Moreira \& Massarani, 2002).

Nesse sentido, pode-se argumentar que a própria Academia tem dado insuficiente importância às atividades de divulgação científica como parte da formação de seus pesquisadores. É assim que, no aprendizado da prática científica, raramente se discute a atividade de divulgação de procedimentos e resultados para outros segmentos que não o dos próprios pares. É revelador, por exemplo, o fato de que a maior parte dos manuais de métodos de pesquisa em ciências sociais sequer considera essa divulgação como parte do processo de pesquisa.

\section{Objetivos}

Nesse contexto, a proposta do trabalho aqui apresentado foi a criação de um programa semanal, intitulado Fora do ar: sintonizando a psicologia no seu dia a dia, veiculado pela Rádio UFMG Educativa desde novembro de 2008. Pretende-se, com esse programa, possibilitar a articulação de atividades de ensino, pesquisa e extensão a partir dos seguintes objetivos: a) ensino: possibilitar, aos envolvidos diretamente na realização dos programas, leituras, debates e práticas que permitam lidar, de forma crítica e ética, com questões de divulgação do conhecimento científico, considerando os aspectos específicos da circulação de informações na sociedade brasileira contemporânea; b) pesquisa: fornecer ao envolvidos atividades diretamente relacionadas a procedimentos de pesquisa, como revisão bibliográfica, identificação de pontos teórica e socialmente relevantes sobre determinado tema, produção de material de divulgação de resultados de investigação científica para um interlocutor não especialista e c) extensão: criação de espaço para discutir, que se pretende 
democrático pelo tratamento diferenciado, mas não hierarquizado, sobre os diversos saberes em circulação na sociedade.

\section{Descrição das atividades}

Equipe: a equipe responsável pela realização do programa conta com quatro alunos do Curso de Graduação em Psicologia/FAFICH/ UFMG, além de um professor coordenador do Departamento de Psicologia/FAFICH/ UFMG.

Foram produzidos, até o momento, 30 programas, com duração média de 15 minutos cada, sobre os seguintes temas: transtornos alimentares; Freud explica (difusão da psicanálise na linguagem cotidiana); preconceito racial; e agora, José? (orientação profissional); TDAH - a mil por hora; Natal e consumismo; psicólogos e catástrofes; adolescência; Ano Novo e esperança; modismos; de novo longe de casa (migração); vida urbana; aborto; mulheres no topo de carreira; intolerância à diversidade sexual; depressão; racismo; discriminação por classe social; intolerância à diversidade religiosa; memória e esquecimento; tradição; memória e mídia; trauma; dislexia; discalculia; relação entre professores e alunos; aprendizagem fora da sala de aula; sociabilidade e internet; saúde; envelhecimento.

Apresentaremos a seguir a estrutura-padrão do programa, com os seus respectivos objetivos e procedimentos:

1. Texto 01 (introdutório): cumpre a função de introduzir o tema a partir de levantamento prévio de informações em periódicos científicos, internet, revistas de circulação semanal e, eventualmente, pequenas entrevistas com não especialistas. É realizada uma breve apresentação dos locutores;

2. Música: é o espaço destinado a apresentar ao público uma produção musical que versa sobre o tema abordado pelo programa e que tem como objetivo contemplar uma perspectiva cotidiana não especializada do tema e, ao mesmo tempo, tornar a programação mais dinâmica, uma vez que os elementos musicais fornecidos ao ouvinte podem fazer com que ele se interesse mais pela discussão proposta. Um outro objetivo seria o de possibilitar que as pessoas escutassem, de maneira diferenciada, canções populares que veiculam, como toda produção cultural, um conjunto de descrições e avaliações relativas a diferenciadas inserções sociais de compositores e intérpretes;

3. Texto 02 (discussão): após uma breve alusão à canção veiculada, indicamos alguma possível abordagem psicológica do tema. Tal abordagem deverá ser apresentada de forma acessível ao ouvinte, com o propósito de esclarecer alguns pontos que sejam eventualmente mais complexos. O objetivo desse espaço é mostrar ao ouvinte que eventos correntes no seu dia a dia são fenômenos estudados pela Psicologia e que esta possui, portanto, algo a dizer sobre eles. Reiteramos que não se almeja estabelecer uma hierarquia entre os saberes do público ouvinte e os conhecimentos formulados pela Psicologia, mas sim, demonstrar como ambos se relacionam;

4. Entrevista: nesse espaço, dá-se voz a profissionais que possam aprofundar, a partir de sua experiência profissional, pontos específicos do tema proposto pelo programa; a entrevista realizada com profissionais da área possui ainda dois outros objetivos complementares: (I) possibilitar uma discussão diferenciada sobre o tema guiada por graduandos em Psicologia, a partir de revisão prévia de literatura, e (II) convidar o entrevistado a veicular informações sobre seu campo de trabalho com uma linguagem mais acessível a um público-alvo que desconhece as especificidades de sua área de atuação; 
5. Sugestões de filmes: sugestões de filmes relacionados aos assuntos tratados;

6. Expediente: informações sobre a produção do programa e apoios institucionais. Contato e página na internet.

O processo de produção de cada programa compreende as seguintes atividades: reunião para decisão sobre o tema do programa, revisão bibliográfica, redação do texto-base, escolha da música a ser veiculada e do filme sugerido, realização da entrevista, edição da entrevista, revisão do texto final, gravação da locução e edição final, veiculação, avaliação do programa.

As descrições de cada uma dessas atividades se encontram abaixo:

\section{Reunião para decidir o tema do programa}

Em reuniões semanais, o grupo decide as temáticas a serem abordadas pelos programas. Seguindo os objetivos acima apresentados, o critério da escolha passa, primeiramente, pela identificação de assuntos/temáticas que possibilitem discussões que integrem algum ponto de vista da Psicologia e outras interpretações não acadêmicas. Posteriormente, usamos critérios mais práticos, como a possibilidade de encontrar um entrevistado que trabalhe com a temática escolhida e a existência de música ou de alguma outra produção cultural sobre o assunto. Inicialmente, a escolha era feita entre temas livres, como, por exemplo, aborto, transtornos alimentares, consumismo. Mais recentemente, passamos a produzir blocos compostos de quatro programas, todos sobre a mesma temática maior, mas com especificações que os diferenciam. Podemos citar, como exemplo, o bloco produzido sobre a temática memória, que é composto por quatro programas que compreendem visões e fenômenos diferentes sobre a memória: memória e esquecimento, memória e tradição, memória e mídia e memória e trauma. Essa mudança de procedimento se deu, também, com o intuito de tentar resolver um problema encontrado na produção de programas livres: o curto tempo, anterior à veiculação, que os participantes tinham para elaborar os programas. Através da criação dos blocos, as temáticas passaram a ser determinadas com maior antecedência, o que dava ao responsável pelo programa mais tempo para pesquisar.

\section{Revisão bibliográfica}

A partir do tema escolhido, realizamos, em bases de periódicos on-line, revistas semanais e livros, um levantamento bibliográfico sobre o assunto do programa. O objetivo de tal revisão é possibilitar que seja elaborado um texto-base e questões para a entrevista.

\section{Redação do texto-base}

Essa tarefa é realizada por apenas um dos membros da equipe. O texto-base consiste no texto inicial (introdutório, contendo a apresentação do tema e dos locutores, como anteriormente descrito), além da definição de uma estrutura das ideias a serem desenvolvidas. No texto-base, encontramse os tópicos que serão utilizados para a elaboração do roteiro da entrevista.

\section{Escolha da música a ser veiculada e da produção cultural sugerida}

Parte importante de cada episódio do programa é representada pela música. As canções, quase exclusivamente cantadas em língua portuguesa, apresentam-se como manifestações do saber popular, não acadêmico. Seu papel como representante desse saber em particular é dialogar com as 
outras partes do programa: com a entrevista/ entrevistado e com os aportes teóricos usados como referência. Para tanto, naturalmente, são veiculadas canções cujo tema central seja relacionado ao tema abordado pelo programa.

Entretanto, é comum que essa relação não seja direta ou explícita. Esse obstáculo é contornado através da apresentação da música, pequeno trecho em que o locutor chama a atenção do ouvinte para o ponto da canção que mais se refere ao tema. É também nessa apresentação que o locutor se encarrega de indicar o nome dos compositores, intérpretes e ano de lançamento da canção ou de sua versão específica, conforme o caso.

Comumente, cada episódio se encerra com uma sugestão de produção cultural que, tal qual a música, aborda o tema referente ao programa em questão. O habitual é que essa sugestão cultural se apresente como um filme, mas já foram sugeridos livros e histórias em quadrinhos, sempre obras de fácil acesso.

\section{Realização das entrevistas}

Como citado anteriormente, as entrevistas com profissionais podem ser tomadas como representantes do saber acadêmico tanto quanto as canções representam o saber popular. Para tanto, algumas restrições são estabelecidas, como a necessidade de que o entrevistado seja, obrigatoriamente, possuidor de formação na área da Psicologia.

A etapa da entrevista se inicia quando, definido o tema de trabalho e tendo sido selecionada alguma biografia de base, a equipe de produção procura, através de indicações ou de buscas por assunto em plataformas específicas (como o sistema de currículos Lattes) algum profissional cuja área de atuação/pesquisa mais se aproxime do tema escolhido. Isso feito cabe ao produtor responsável pelo episódio entrar em contato com o possível entrevistado. O primeiro contato é feito através de e-mail. Nesse primeiro contato, o produtor, através de um texto padronizado, apresenta ao entrevistado um pequeno histórico do projeto e convida-o a conceder a entrevista.

Caso o entrevistado resida em Belo Horizonte/ MG, a entrevista é realizada pessoalmente. Se esse contato não é possível, a entrevista pode ser feita através de telefone.

$\mathrm{Na}$ realização das entrevistas, a maior dificuldade tem sido conciliar os horários dos profissionais com a dos produtores/ entrevistadores e, mais ainda, com a disponibilidade do equipamento necessário. Outra dificuldade relativa às entrevistas diz respeito à qualidade sonora das gravações obtidas. Os aparelhos para gravação digital mais comumente disponíveis possuem baixa amplitude de captação, e a qualidade da gravação depende muito do ambiente em que se realiza a entrevista. Essas dificuldades têm levado a equipe a, cada vez mais, preferir a realização de entrevistas por telefone, mesmo quando há a possibilidade de serem feitas pessoalmente. $\mathrm{O}$ som captado diretamente da linha telefônica apresenta maior qualidade, sobretudo quando se considera a possibilidade técnica de limpar outros sons que não os da própria voz do(a) entrevistado(a).

\section{Edição da entrevista}

Em média, as entrevistas têm a duração de 20 a 35 minutos antes da edição. No formato final do programa, apenas um quinto desse total, aproximadamente, será levado ao ar. A edição da entrevista é feita pelo próprio entrevistador, e visa, além de ressaltar os pontos principais do discurso do entrevistado, a promover uma amarração adequada entre a fala do profissional, acadêmica, e os demais componentes do programa, como a 
canção e os textos de locução, baseados na bibliografia consultada.

Durante o processo de edição da entrevista, tem-se a atenção redobrada para que a exclusão de algum trecho da fala do entrevistado ou a aproximação de dois trechos distintos não deturpe ou permita uma interpretação errada das ideias expostas pelo(a) entrevistado(a).

Os trechos de entrevista, então, são inseridos no texto do programa, sendo precedidos por uma espécie de chamada, que apresenta ao ouvinte o(a) entrevistado(a) (nome, formação e vínculo institucional). Entre dois trechos de entrevista, insere-se um pequeno texto denominado passagem. Na passagem, o locutor parafraseia o que foi dito pelo entrevistado no primeiro trecho e antecipa o segundo, adicionando dinamismo ao produto final.

\section{Revisão do texto final}

Após a estruturação do texto do programa já com a música, os trechos da entrevista e a indicação de filme, é realizada uma revisão, verificando-se a coerência do texto, o não uso de jargões da Psicologia e se o texto escrito possibilita uma boa locução e um bom entendimento pelos ouvintes. Se julgarmos necessário realizar alterações no texto, o responsável pelo programa reorganiza o mesmo com as modificações que foram propostas pelo grupo.

\section{Gravação da locução e edição final}

Quando o texto do programa já foi revisado e o responsável por ele já realizou as alterações necessárias, ele pode ser gravado. As locuções são realizadas no estúdio da Rádio UFMG Educativa, em horários previamente combinados com os técnicos responsáveis pela edição dos programas.
Após a locução do texto escrito, o membro da equipe que a realizou acompanha a inserção dos trechos da entrevista e da música no arquivo final, dando as orientações necessárias ao técnico da edição.

\section{Veiculação}

Os programas são veiculados duas vezes por semana: na quinta-feira, às $23 \mathrm{~h} 15 \mathrm{~min}$., e na terça-feira da semana seguinte, no mesmo horário (reprise).

\section{Avaliação do programa}

Semanalmente, avalia-se o último programa que foi ao ar, considerandose qualitativamente seu aspecto técnico (locução, som das entrevistas, edição) e sua forma/conteúdo. Esse último elemento avaliado refere-se ao objetivo anteriormente explicitado de promover, no tratamento de um tema específico, uma interlocução não hierarquizada entre diferentes saberes.

\section{Principais desafios, possibilidades de solução e próximos passos}

\section{Principais desafios}

Dois desafios têm sido recorrentemente discutidos pela equipe responsável pelo programa: 1) como contemplar de forma adequada a complexidade teórica de uma área científica em um programa que possui apenas 15 minutos e 2) como utilizar uma linguagem que possibilite o diálogo entre diferentes formas de saber, preservando suas especificidades, sem recriar uma hierarquia entre as mesmas. Está claro que essas questões precisam ser enfrentadas por várias propostas de divulgação científica. 


\section{Possibilidades de solução}

Apresentaremos aqui algumas tentativas, certamente ainda frágeis, de lidar com os desafios acima apontados. Em relação à primeira (complexidade $x$ tempo), pareceunos uma boa estratégia a proposição de blocos temáticos. Esses blocos, ainda que não esgotem o tratamento de um determinado tema pela Psicologia, têm nos possibilitado contemplar, em cada programa, o tratamento de um subtema por uma área específica do saber psicológico. Assim, por exemplo, para o bloco cujo tema geral era memória, produzimos programas sobre os subtemas trauma, com uma perspectiva psicanalítica, tradição, com uma perspectiva fenomenológica, esquecimento, com uma perspectiva cognitivista, e memória e mídia, com uma perspectiva baseada no estudo das subjetividades contemporâneas. Tal estratégia parece ter tido como resultado boas introduções sobre cada um desses subtemas.

Quanto ao segundo desafio (linguagem), uma das maiores dificuldades enfrentadas é a definição do público-alvo do programa Fora do Ar. Ainda que a proposta inicial do projeto tenha sido a produção de um programa destinado ao público em geral, seja pela natureza da proposta de programação de uma rádio universitária, seja pela nossa recusa em produzir um programa-consultório, os comentários recebidos, pessoalmente ou por e-mail, sobre o programa vieram exclusivamente de professores e de graduandos de Psicologia. Ainda assim, consideramos que o programa por nós produzido deveria ser o mais acessível possível a todos os públicos, admitindo-se, é claro, as exigências próprias de um veículo como o rádio (linguagem clara e direta). Para tentar alcançar esse objetivo, decidimos investir em um procedimento que permita uma avaliação externa mais sistemática da forma e do conteúdo dos programas já produzidos pela equipe. Tal procedimento será descrito na próxima seção.

\section{Próximos passos}

Com o intuito de obter informações que possam auxiliar na avaliação dos programas, estamos desenvolvendo um questionário que será enviado, com um link para a audição de um dos episódios já produzidos, em um primeiro momento, aos membros de algumas comunidades virtuais formadas a partir do interesse pela área de Psicologia, e, posteriormente, aos membros de outras comunidades virtuais com interesse em outras áreas. Os objetivos principais desse questionário/procedimento são: (I) definir com mais precisão o público do programa Fora do $A r$, (II) levantar informações quanti e qualitativas sobre o programa, mapeando seus pontos fortes e fracos, (III) possibilitar o desenvolvimento de um instrumento eficaz e prático para a avaliação externa do programa, de maneira que seja possível, posteriormente, ampliá-lo e empregá-lo na avaliação de programas similares e (IV) divulgar o próprio programa e o campo da divulgação científica entre possíveis interessados pela área de Psicologia.

Com o objetivo de contemplarmos de forma mais abrangente o caráter de extensão universitária de nossas atividades, outra ação que identificamos como relevante foi a inclusão, em todos os programas, de informações sobre serviços psicológicos gratuitos voltados para a comunidade. Um levantamento inicial desses serviços já foi realizado, gerando uma lista de telefones e endereços de algumas instituições bem como do perfil do público atendido por elas. Seus responsáveis já estão sendo contatados a fim de obtermos as autorizações para a veiculação dessas informações aos ouvintes. 
Nos programas em fase de preparação, também serão inseridos trechos de entrevistas realizadas em locais públicos com pessoas que se disponham a responder a perguntas breves e diretas sobre o tema principal dos programas. A veiculação desses trechos estará condicionada a sua autorização expressa por esses entrevistados. Da mesma forma que as entrevistas feitas com os psicólogos, essas também serão editadas, priorizandose respostas curtas e concisas, que possam ser utilizadas na íntegra. Tal recurso tem como objetivo multiplicar os pontos de vista sobre determinado tema, trazendo-os para o debate.

\section{Considerações finais}

Reiteramos aqui a importância da divulgação, para um público não especialista, do conhecimento produzido pela área da Psicologia. Parece-nos que tal tarefa não pode ser mais considerada como um simples adendo no processo de formação dos nossos profissionais (pesquisadores ou não). $\mathrm{O}$ investimento progressivo em atividades de formação que proporcionem capacitação para divulgar conhecimento científico pode nos conduzir ao estabelecimento de uma relação mais adequada com o conjunto da sociedade, seja por proporcionar maior visibilidade ao que tem sido produzido na Academia, sobretudo com dinheiro público, seja por fomentar o reconhecimento de que a ciência é, por natureza, um empreendimento coletivo (Silva, 2006). Nesse sentido, consideramos que propostas que procurem enfrentar as dificuldades típicas da tradução de saberes podem contribuir efetivamente para que a ciência se torne acessível a todos os que se interessam pelas contribuições que ela pode oferecer para a melhoria das nossas condições sociais, culturais e econômicas, o que parece ser o caso de toda a população (Maciel \& Silva Jr., 2006; Sabbatini, 2004; Caldas, 2003). 
Adriano Roberto Afonso do Nascimento

Doutorado em Psicologia pela Universidade Federal do Espírito Santo. Professor adjunto do Departamento de Psicologia da Universidade Federal de Minas Gerais e professor-orientador do Programa de Pós-Graduação em Psicologia/FAFICH/Universidade Federal de Minas Gerais, MG - Brasil.

E-mail: nascimento@fafich.ufmg.br

\section{Isabela Dias Ribeiro}

Estudante de graduação da Universidade Federal de Minas Gerais, MG - Brasil.

E-mail: isabeladiasr@gmail.com

\section{Isabella Ferraz Lacerda de Mello}

Graduada pela Universidade Federal de Minas Gerais, MG - Brasil.

E-mail: ferrazisa@gmail.com

\section{Lucas Eduardo Guimarães}

É investigador da Polícia Civil do estado de Minas Gerais, atuando no Núcleo de Psicologia e Serviço Social da Divisão de Referência da Pessoa Desaparecida (NUPSS/DRPD), Minas Gerais, MG - Brasil.

E-mail: lucas.edguima@yahoo.com.br

\section{Luciano Inácio Mariano}

Graduado pela Universidade Federal de Minas Gerais, MG - Brasil.

E-mail: lucianoi_mariano@yahoo.com.br

Endereço para envio de correspondência:

Departamento de Psicologia/FAFICH/UFMG, Avenida Antônio Carlos, 6627 - Campus Pampulha/UFMG, Belo Horizonte-MG. CEP: 31270-901

Recebido 16/4/2010, 1a Reformulação 12/7/2011, Aprovado 12/8/2011. 


\section{Referências}

Albagli, S. (1996). Divulgação científica: informação científica para a cidadania? Ciência e Informação, 25(3), 396-404.

Assumpção, Z. A. (2003). Rádio universitária: vetor de comunicação científica entre especialista e radiouvinte. Publicatio UEPG, 11(1), 39-49.

Caldas, G. (2003). Comunicação, educação e cidadania: o papel do jornalismo científico. In E. Guimarães (Org.), Produção e circulação do conhecimento: política, ciência e divulgação (pp. 73-80). Campinas, SP: Pontes

Deus, S. (2003). Rádios universitárias públicas: compromisso com a sociedade e com a informação. Em Questão, 9(2), 327-338.

Gonçalves, E. M. (2008). Divulgação científica da pesquisa brasileira: um diagnóstico da revista Scientific American Brasil. Contemporânea, 6(01), 1.30. Recuperado em 22 setembro de 2008 de http://revcom.portcom.intercom.org.br/index.php/ contemporanea/article/view/5067/4683

Guimarães. E. (2001). O acontecimento para a grande mídia e a divulgação científica. In E. Guimarães (Org.), Produção e circulação de conhecimento: estado, mídia, sociedade (pp. 13-20). Campinas, SP: Pontes.

Jovchelovitch, S. (2008). Os contextos do saber: representações, comunidade e cultura (P. Guareschi, Trad.). Petrópolis, RJ: Vozes.

Maciel, B., \& Silva Jr., L. S. (2006). O rádio como consultório: do discurso científico ao discurso popular. Texto on-line, 1-9. Recuperado em 20 setembro 2008 de www.betaniamaciel. com/textos/2006lusocom.pdf

Moreira, I. C., \& Massarani, L. (2002). Aspectos históricos da divulgação científica no Brasil. In I. C. Moreira, L. Massarani, \& F. Brito (Orgs.), Ciência e público: caminhos da divulgação científica no Brasil (pp. 43-64). Rio de Janeiro: Casa da Ciência - Centro Cultural de Ciência e Tecnologia da UFRJ; Fórum de Ciência e Cultura.
Moscovici, S. (1978). A representação social da psicanálise (A. Cabral, Trad.). Rio de Janeiro: Zahar Editores.

Mueller, S. P. M. (2002). Popularização do conhecimento científico. DataGramaZero- Revista de Ciência da Informação, 3(2), 1-8. Recuperado em 20 setembro 2008 de http://www. dgz.org.br/abr02/Art_03.htm.

Oliveira, F. (2001). Comunicação pública e cultura científica. Parcerias estratégicas, 13, 201-208. Recuperado em 20 setembro 2008 de http://ftp.mct.gov.br/CEE/revista/ parcerias13/10.pdf

Pechula, M. R. (2007). A ciência nos meios de comunicação de massa: divulgação de conhecimento ou reforço no imaginário social? Ciência \& Educação, 13(2), 211-222.

Ruivo, M. C. (2004). A ciência tal qual se faz ou tal qual se diz? In B. S. Santos (Org.), Conhecimento prudente para uma vida decente (pp. 585-599). São Paulo: Cortez.

Sabbatini, M. (2004). Alfabetização e cultura científica: conceitos convergentes. Ciência e Comunicação, 1(1), 1-14. Recuperado em 24 setembro 2008 de http://www.jornalismocientifico.com. br/revista1artigomarcelosabbatini.htm

Silva, H. C. (2006). O que é divulgação científica? Ciência \& Ensino, 1(1), 53-59.

Werneck, E. F. (2002). E por falar em ciência... no rádio! In I. C. Moreira, L. Massarani, \& F. Brito (Orgs.), Ciência e público: caminhos da divulgação científica no Brasil (pp. 79-88). Rio de Janeiro: Casa da Ciência - Centro Cultural de Ciência e Tecnologia da UFRJ; Fórum de Ciência e Cultura. 